\section{Understanding How Inequality in the Distribution of Income Affects Health}

\author{
JOHN W. LYNCH \\ University of Michigan, USA
}

GEORGE A. KAPLAN

University of Michigan, USA

jo h n w. 1 y n ch (PhD, MPH University of California, Berkeley and MEd University of Western Australia) is Assistant Research Scientist at the Department of Epidemiology, School of Public Health and at the Institute of Social Research, University of Michigan, USA.

g e o r g e a . k a pl a n (PhD Cornell University and BA Johns Hopkins University) is Professor and Chair of the Department of Epidemiology, School of Public Health, University of Michigan, USA.
Journal of Health Psychology

Copyright (C) 1997 SAGE Publications

London, Thousand Oaks and New Delhi, ISSN: 1359-1053 Vol 2(3) 297-314

\section{Abstract}

Research on the determinants of health has almost exclusively focused on the individual but it seems clear we cannot understand or improve patterns of population health without engaging structural determinants at the societal level. This article traces the development of research on income distribution and health to the most recent epidemiologic studies from the USA that show how income inequality is related to ageadjusted mortality within the 50 States. $(r=-0.62, p=$ $0.0001)$ even after accounting for absolute levels of income. We discuss potential material, psychological, social and behavioral pathways through which income distribution might be linked to health status. Distributional aspects of the economy are important determinants of health and may well provide one of the most pertinent indicators of overall social well-being.

\section{Keywords}

income inequality, pathways, population health 
in $\mathrm{th}$ is a rticle, we are concerned with exploring the question of how inequality in the distribution of income affects patterns of population health. It is well-established that individual income level affects health, but income distribution is a characteristic of a social system-it is not measurable in individuals. Research on the determinants of health has almost exclusively focused on the individual, and this is certainly true in the field of health psychology, but it seems clear that we cannot understand or improve patterns of population health without engaging structural determinants at the societal level (Morris, 1990; M. Susser, \& E. Susser, 1996).

One of our goals is to advance thinking about health inequalities by moving from consideration of individual characteristics like income, or education, to properties of the social and economic systems in which people play out their daily lives. These structural properties may have important influences on health over and above the characteristics of the individuals who comprise these populations (Haan, Kaplan, \& Camacho, 1987; Kaplan, 1996; Macintyre, MacIver, \& Sooman, 1993). This should not be taken to mean that individual characteristics are unimportant determinants of health, but clearly there are structural aspects of our societies that play a large role in determining how individuals are sorted into the groups who receive good educations, get good jobs and receive adequate financial compensation. We believe that income inequality may be an important measure of one of these structural characteristics.

\section{The background}

The form of law which I should propose as the natural sequel would be as follows:

In a state which is desirous of being saved from all plagues ... there should exist among the citizens neither extreme poverty, nor, again, excess of wealth, for both are productive of both these evils. Now the legislator should determine what is to be the limit of poverty or wealth. Let the limit of poverty be the value of the lot; this ought to be preserved, and no ruler, nor any one else who aspires after a reputation for virtue, will allow the lot to be impaired in any case. This the legislator gives as a measure, and he will permit a man to acquire double or triple, or as much as four times the amount of this. (Plato, Laws, cited in Fraser, 1995, p. 528)

Concerns about social inequality are not new. They have been voiced throughout human history, and are germane to ideas of democracy and justice. For a variety of reasons inequality has often been seen as an undesirable characteristic of a society, because of its potentially disruptive effects on civic functioning, or its implications for the rise of reactionary political movements, or because of its offense to moral sensibilities. However, arguments have also been advanced that social inequality is merely the institutional reflection of 'natural' individual differences in abilities and intelligence (Herrnstein \& Murray, 1994). Both positions remain firmly entrenched in popular and scientific debates about economic, racial/ethnic and gender inequalities (Fischer, et al. 1996; Lewontin, 1991; Lewontin, Rose, \& Kamin, 1984; Muntaner, Nieto, \& O'Campor, 1996; Will, 1995). Scientific interest in this field would perhaps be limited to politics, philosophy, economics and sociology were it not for the overwhelming body of evidence that shows how social and economic inequalities are one of the most profound determinants of population health (Lynch, 1996). Almost without regard to how health status and position in the social structure have been measured, those with lower social and economic status experience poorer health (Antonovsky, 1967; Carroll, Davey Smith, \& Bennett, 1996; Haan, Kaplan, \& Syme, 1989; Kaplan \& Keil, 1993; Krieger, Rowley, Hermann, Avery, \& Phillips, 1993; Lynch, et al., 1994; Lynch, Kaplan, R. Salonen, Cohen, \& J. Salonen, 1995; Lynch, 1996; Lynch, Kaplan, \& J. Salonen, 1997; Marmot et al., 1991; Syme, 1992).

The vast majority of studies that have documented socio-economic health inequalities have conceptualized and measured socio-economic status (SES) as a property of an individual, and compared the health status of groups of individuals who differed in regard to their income, education or occupation. In this way, 'inequalities' in health status are due to the fact that individuals differ according to their educational achievement, or their absolute levels of income. Indeed, this makes sense because the skills and economic resources held by individuals are 
likely to influence things such as the type of housing they can afford, the neighborhood they live in, the quality of food they buy, or their access to leisure physical activity. However, it also leaves open the interpretation that there are other individual characteristics that explain why they have lower educational achievement, are not very well paid, or have 'bad' jobs - they are unintelligent, sick, lazy or genetically inferior. This focus on measuring SES as an individual characteristic has also been conceptually and methodologically consistent with the rise of modern, risk factor epidemiology which has focused almost exclusively on finding the individual biological, behavioral and psychosocial correlates of disease.

\section{The literature on inequality of income distribution and health}

The link between low income and poor health is highly consistent when individuals are compared within a country, but there is little association between low income and health status when compared across countries. Countries with higher average incomes do not invariably have better overall health status. For instance, Sen (1993) showed that Saudi Arabia and the Kerala region of India had similar life expectancies at birth of around 70 years, yet the absolute level of average income in Saudi Arabia was more than 30 times greater than that in Kerala. Similarly, average life expectancy at age 5 in Bangladesh was greater than it was for African Americans living in parts of New York City, despite the fact that African Americans on average had higher absolute incomes (McCord \& Freeman, 1990). In this section of the article, we will briefly trace the development of research on income distribution and health from the early work in health economics and demography that focused on average absolute income level, to the most recent epidemiologic studies that have examined the health impacts of income distribution per se.

\section{Part I}

The need to look beyond the absolute level of income to understand its association with health status, became crystallized when mortality and life expectancy differences between countries were examined in relation to average income level. Evidence suggesting a relationship between income distribution and health began to accumulate in 1969, when Auster, Leveson and Sarachek (1969), in a comparison of the 50 United States, showed that average income tended to be positively associated with mortality. This surprising finding was not consistent with other evidence collected at the individual level. Fuchs (1974) found that per-capita income was not related to adult mortality in comparisons between developed countries.

In a seminal study, Preston (1975) examined the association between per-capita national income and life expectancy at birth, for three different decades of the twentieth century. He demonstrated that life expectancy in the 1900s, 1930s and 1960s exhibited a non-linear relationship with per-capita national income. Above a certain threshold, gains in life expectancy were not related to higher levels of average income. In addition, the relationship between income and life expectancy had shifted upwards during the twentieth century.

Preston made several points in discussing these findings that are pertinent to the topic of this article. First, he proposed that upward shifts in the life expectancy-income association were mainly due to 'exogenous' factors that strengthened the public health infrastructure (immunization, technological advances and specific disease-control campaigns) rather than income growth per se. Second, he suggested that over time, life expectancy had become progressively more dissociated from absolute income level and that at least some of the variation in life expectancy at the upper-income levels was likely due to variations in income distribution between countries.

Preston could not examine this issue in detail because the available data were inadequate, but he did show mathematically how income distribution could affect the total mortality burden of a population. He explained that because the association between income and life expectancy was asymptotic (increases in income produced diminishing returns on increased life expectancy), those with incomes below the average lost more years of life, than were gained by those with higher than average incomes. The non-linear association between income and mortality has been reported in some more recent studies on large US data sets (Backlund, Sorlie, 
\& Johnson, 1996; Pappas, Queen, Hadden, \& Fisher, 1993). Preston concluded that 'The distribution of income is clearly a likely source of variance in the basic relation between national life expectancy and average national income' (1975, p. 242).

Rodgers (1979) elaborated graphically and mathematically how income distribution was associated with population health. Additionally, in a sample of about 50 countries, he empirically tested a model that predicted life expectancy at birth, at age 5 and infant mortality as a function of mean income level, and income distribution. $\mathrm{He}$ found that income distribution was significantly and consistently related to mortality, after controlling for mean income (which was also an important predictor), and commented that 'The results for life expectancy at birth suggest that the differences in average life expectancy between a relatively egalitarian and a relatively inegalitarian country is likely to be as much as five to ten years' (p. 350).

\section{Part II}

Somewhat surprisingly, since these intriguing early findings, the relationship between income distribution and health has not been widely studied. Le Grand (1987) explored how different measures of inequality were related to mortality, and found that the greater the extent of inequality, the higher was the mortality. One of the most widely used measures of income distribution is the Gini coefficient. The Gini coefficient is an overall measure of income inequality derived from the relationship between cumulative proportions of the population, plotted against cumulative proportions of income. The Gini is calculated by comparing the area under the diagonal with the area under the actual income distribution, called the Lorenz curve. The Gini ranges from 0 - perfect equality, to 1 -perfect inequality of income distribution (Cowell, 1995). Perfect income distribution would be achieved if 10 percent of the population received 10 percent of the total income; 20 percent of the population received 20 percent of the total income and so on. If each percentile of the population received the equivalent share of total income, then the Gini coefficient would be 0 . However, if only one household in the population received all the income, the Gini would be 1 .
Flegg (1982) examined infant mortality in a sample of less developed countries in terms of per-capita income, and the Gini coefficient, and found that absolute income was negatively related, and the Gini coefficient positively related to infant mortality. Weatherby, Nam and Isaac (1983) in a study of female mortality over the age of 50 years in a sample of 38 countries, found that countries with higher levels of income inequality had higher female all-cause mortality for ages 50-64, although the pattern of cause-specific mortality was not uniform among age groups. They also pointed out that the mortality effects of income inequality may be even stronger at ages less than 50. Pampel and Pillai (1986) used the Gini coefficient to examine infant mortality rates in 18 developed nations and found some support for the effect of income inequality. In a sample of 41 developed and developing countries Waldmann (1992) showed that the greater the total income share held by the top 5 percent of the population, the higher was the infant mortality. This finding received some support from another analysis of between 34 and 61 developing countries conducted by Crenshaw and Ameen (1993).

Wennemo (1993) used data from the Luxembourg Income Study to compare infant mortality in 18 industrialized countries, and confirmed that income inequality and relative poverty were of greater importance in understanding variations in infant mortality between countries, than was the absolute level of economic development. In another study, that used a measure of the average income received by the bottom 10 percent of the population, although not strictly a measure of income distribution, Duleep (1995) argued that even for economically advanced countries, income inequality was an important determinant of mortality. In 1993, Merva and Fowles, used econometric modeling of cause-specific mortality and crime rates in 28 major metropolitan areas of the United States to examine the impact of unemployment, poverty and wage inequality. Among other things, they found that wage inequality was not associated with suicide, cardiovascular or stroke mortality, but was significantly related to homicides, accidents, aggravated assaults, larceny and motor vehicle thefts.

In a series of articles produced since the mid 1980s Richard Wilkinson has demonstrated 


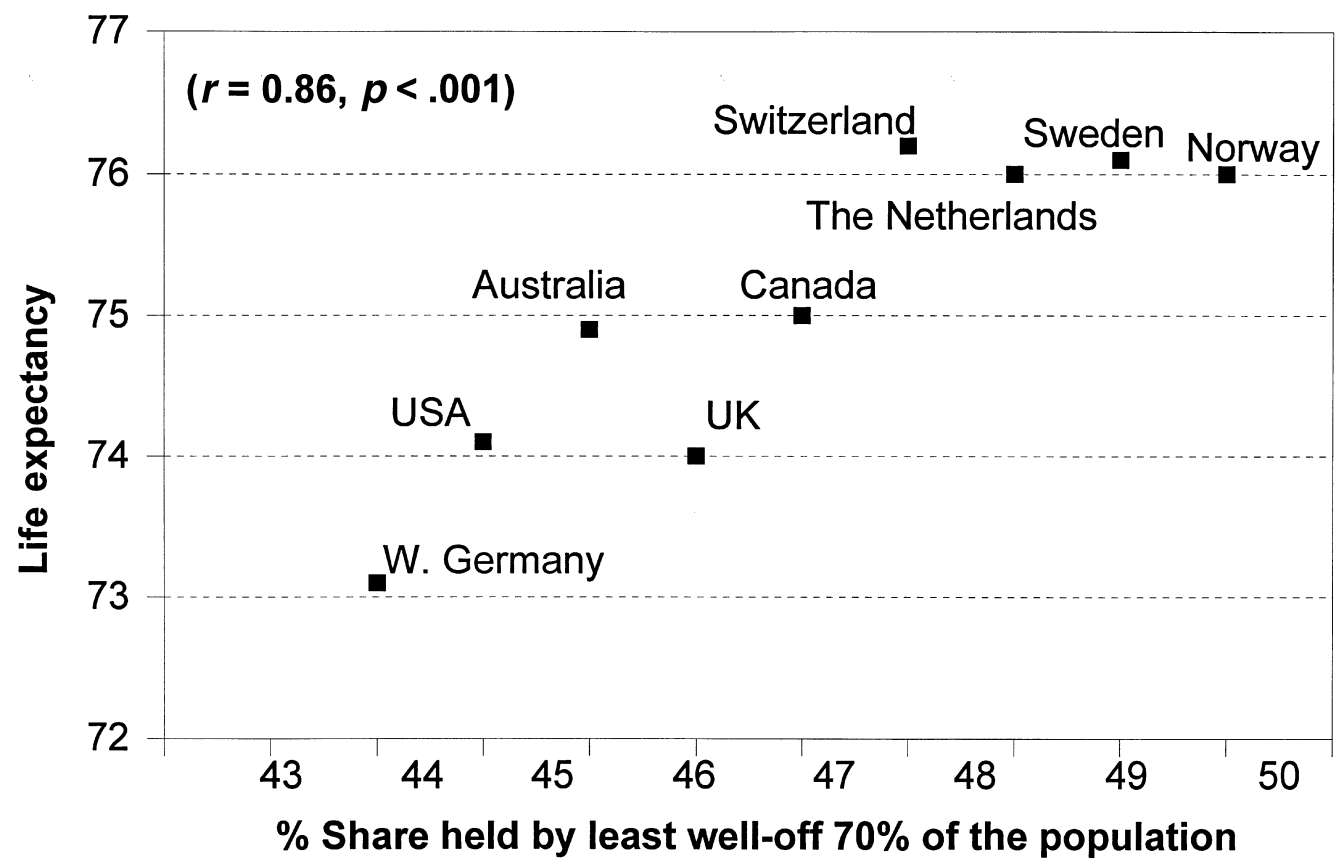

Figure 1. Association between life expectancy at birth and the share of post-tax and benefit income held by the least well-off 70 percent of the population (adapted from Wilkinson, 1992).

important associations between income inequality and differences in mortality between industrialized countries (Wilkinson, 1986, 1989, 1993a $\& b, 1995)$. His most widely cited study, published in 1992, using income data from the Luxembourg Income Study, showed that the percentage share of total post-tax and benefit income held by the least well-off 70 percent of the population was cross-sectionally related to life expectancy at birth. This association was unaffected by adjustment for average absolute income level and was evident across a range of decile shares of the income distribution (Figure 1). Furthermore, using two other data sources, he showed how changes in income share were associated with changes in life expectancy. Wilkinson made extremely important observations not just because they could shed light on why income and health were related within, but not between countries, but because they had direct relevance to economic and public health policy.

\section{Part III}

A study by Ben-Shlomo, White and Marmot (1996) uses a measure of the variation in deprivation, as well as the absolute level of deprivation across local authority areas in Britain to show how both these factors contributed to mortality, although the absolute level appeared to be more strongly associated. In an intriguing analysis of post-transition countries in East Europe, Davey Smith and Egger (1996) report strong relationships between income inequality and life expectancy (1991-1993), as well as changes in inequality between 1987 and 1993 and changes in life expectancy over the same period. They comment that 'These countries have undergone a transformation from Stalinist pseudosocialism to the vagaries of the free market, and even the chief cheerleader for unfettered free market capitalism, the World Bank, was forced to ask: Is transition a killer?' (p. 1584).

Some of the most recent empirical work to examine specifically the effects of income inequality on health was conducted by two independent groups of investigators within the United States-George Kaplan's group at the University of Michigan, and by Kennedy, Kawachi and Prothrow-Stith at Harvard. The studies used dif- 
ferent measures of income inequality to examine its association with mortality differences among the 50 United States. (Kaplan, Pamuk, Lynch, Cohen, \& Balfour, 1996b; Kennedy, Kawachi, \& Prothrow-Stith, 1996) These studies are important for a number of reasons. First, they examined the association between variations in state income inequality and mortality differences, at a different level of geopolitical aggregation than that between nations. Second, they overcame many of the data quality problems encountered in the previous between country analyses; and, third, the Kennedy and colleagues' (1996) study enabled an examination of how the association between income inequality and mortality differed by cause of death. (Please note: there were important corrections to these papers, published later in the British Medical Journal 312, 11 May 1996.) Finally, and perhaps most importantly, the study by Kaplan and colleagues (1996b) also examined a number of social and educational correlates of income inequality in an effort to understand how inequality might affect mortality.
Kaplan and colleagues (1996b) showed that the income share held by the least well-off 50 percent of the population in each state, was strongly cross-sectionally associated with overall mortality in $1990(r=-0.62, p=.0001)$. This association was not affected by adjustment for median state income, was observed for almost all percentile shares of the income distribution; was consistent across age groups and in both sexes. Furthermore, the share of total state income held by the least well-off 50 percent of the population was strongly associated with a number of other health outcomes (Table 1), social indicators (Table 2) and educational indicators (Table 3). Moreover, the association between the share of the total income received by the least well-off 50 percent of the state population was consistently more strongly associated with mortality, other health outcomes, social and educational indicators than was the median absolute income in each state.

In prospective analyses, income inequality levels in 1980 predicted changes in mortality

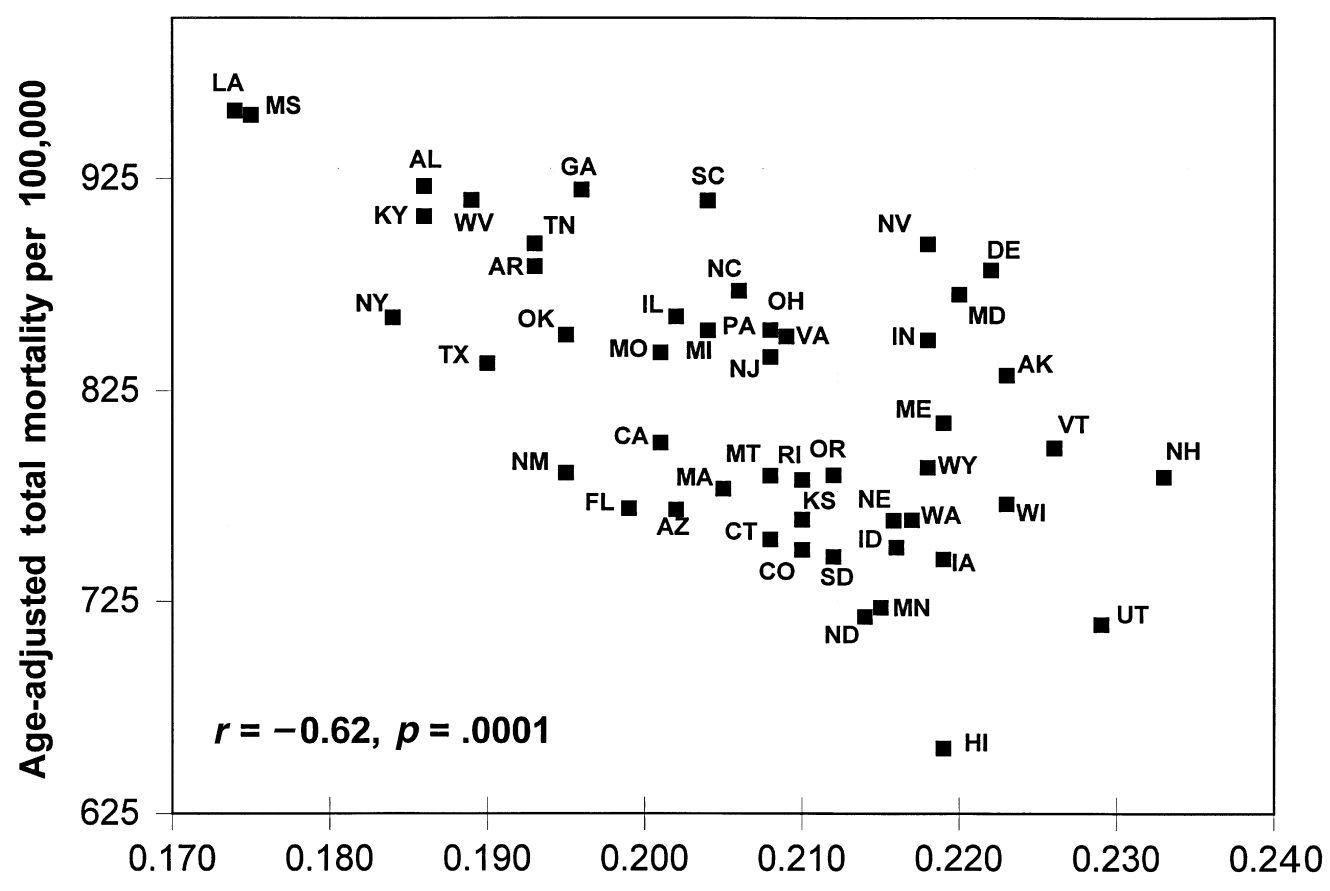

Proportion of total household income received by the least well-off $50 \%$

Figure 2. Association between age-adjusted mortality and the share of total income received by the least welloff 50 percent of the population in the 50 United States, 1990 (Kaplan et al., 1996b). 
Table 1. Correlation between income inequality* and other health related outcomes (adjusted for median state income) (Kaplan et al., 1996b)

\begin{tabular}{lll}
\hline Health outcome & $r$ & $p$ value \\
\hline \% Live Births $(<2500 \mathrm{gm})$ & -0.65 & .001 \\
\% Unable to work due to & -0.33 & .05 \\
$\quad$ disability & & \\
Violent crimes/100K & -0.7 & .0001 \\
Homicides/100K & -0.74 & .0001 \\
Log per capita medical & -0.67 & .001 \\
$\quad$ expenditures & & \\
\% Sedentary & -0.34 & .03 \\
\% Smoker & -0.35 & .02 \\
\% Binge drinkers & 0.32 & .03 \\
\hline
\end{tabular}

* Share of total income held by least well-off $50 \%$.

Table 2. Correlation between income inequality and social indicators (adjusted for median state income) (Kaplan et al., 1996b)

\begin{tabular}{lcl}
\hline $\begin{array}{l}\text { Social indicator } \\
(\%)\end{array}$ & $r$ & $p$ value \\
\hline Unemployed & -0.48 & .001 \\
Prisoners & -0.44 & .01 \\
Aid to families with dependent & -0.69 & .001 \\
children (AFDC) & & \\
Food stamps & -0.72 & .001 \\
No health insurance & -0.45 & .002 \\
\hline
\end{tabular}

Table 3. Correlation between income inequality and educational indicators (adjusted for median state income) (Kaplan et al., 1996b)

\begin{tabular}{lll}
\hline Educational indicators & $r$ & $p$ value \\
\hline \% No high-school degree & -0.71 & .001 \\
\% High-school dropout & -0.5 & .001 \\
4th grade reading & 0.58 & .001 \\
4th grade math & 0.64 & .001 \\
Total education spending & 0.32 & .02 \\
Library books per capita & 0.42 & .003 \\
\hline
\end{tabular}

between 1980 and $1990(r=-0.45, p<.001)$. The higher the level of income inequality in 1980, the slower was the decline in mortality between 1980 and 1990. Simultaneous changes in income inequality and mortality between 1980 and 1990 were weakly related using the income share held by the least well-off 50 percent of the population, but changes in mortality were associated with simultaneous changes in the percentage share held by the least well-off
10 percent of the population $(r=-0.53, p<$ $.001)$.

In similar analyses, Kennedy and colleagues (1996) used the Gini coefficient, and another Lorenz-based measure aptly called the 'Robin Hood Index', that approximated the share of total income from those above the mean that would have to be transferred to those below the mean to achieve equality of distribution, to examine the cross-sectional associations between income inequality and cause-specific mortality. Their findings were entirely consistent with those of Kaplan and colleagues (1996b), and showed how the Robin Hood Index was strongly related to infant mortality, coronary heart disease, malignant neoplasms and homicide (see corrections in $B M J$ cited earlier). They also calculated that each percentage increase in the Robin Hood Index was associated with an increase in total mortality of almost 22 deaths per 100,000. This meant that if Louisiana, the most unequal state, had the income distribution of the least unequal state (New Hampshire) there would be a reduction in the total mortality rate of 150 deaths per 100,000 in Louisiana. Taken together, the studies by Kaplan and colleagues (1996b), and Kennedy and colleagues (1996) have important and provocative implications for research and public policy on the economic determinants of health.

\section{Part IV}

Before proceeding to a discussion of the processes through which income inequality might affect health, we must address the recent criticisms of the research conducted in this field. In 1995, Ken Judge authored a critique of the work linking income inequality with mortality. In his critique, Judge focused exclusively on the work of Wilkinson (1992) and claimed that reanalysis of new data that had been added to the Luxembourg Income Study database (LIS) 'casts doubt on the hypothesis that inequalities in the distribution of income are closely associated with variations in average life expectancy at birth among the richest nations of the world' (p. 1282). More recently, these same criticisms have been repeated by Saunders (1996) who also showed that reanalysis of the updated LIS information failed to support a statistically significant association between income distribution and life expectancy or changes in life expectancy. 
In new analyses, McIsaac and Wilkinson (1995) have shown how differences in response rates between countries recently added to the LIS database might shed some light on the inconsistent findings on life expectancy to which Judge (1995) and Saunders (1996) referred. These criticisms failed to consider the issue of data quality, nor did they provide an explanation for Wennemo's (1993) findings, also based on the newly added LIS data, that showed important associations between income inequality and infant mortality.

Nevertheless, Judge's and Saunders' criticisms of Wilkinson's research from 1992, deserve to be discussed. In our view, there were four basic issues. First, they claimed that there were problems with the validity of some of the data that Wilkinson used, that is, they were differentially unreliable, covered different years, and were not gathered for the purpose of examining income inequality and health. Second, the basic income data that were used to generate distributional measures of inequality were not adjusted for taxes, benefits and household size. The idea here is that use of 'raw' household income distributions would overstate the extent of inequality because neither did they reflect the number of people who were supported by the income in each household nor did they account for governmental policies that tax and transfer money and benefits from the rich to the poor. Third, Judge (1995) and Saunders (1996) claimed that there was no rationale for the selection of the income inequality measure, and the association between income inequality and mortality differed according to which measure was used. They claimed the choice of measure should be based on a theoretical rationale of how income distribution affects health. Finally, Judge argued that any examination of the income inequality, life expectancy association must use multivariate techniques that can adequately control for confounding.

These are potentially important considerations relevant to any study on income inequality and health, so it is indeed unfortunate that they were presented with such a personal focus on Wilkinson's work (1995). However, our purpose in this article is to evaluate the veracity of these criticisms in light of the more recent empirical findings within the United States. The basic points Judge (1995) and Saunders (1996) raised were largely addressed in the studies of income inequality and mortality in the 50 United States (Kaplan et al., 1996b; Kennedy et al., 1996). First, in our study, we used 1980 and 1990 US Census data that was based on pretax income from all sources, including governmental benefits, and examined mortality data from 1979-1981, and 1989-1991 provided by the National Center for Health Statistics in Washington, DC. Thus, the data are of high quality and collected in the same time frame as the mortality information. In addition, we showed that the association between income inequality and mortality was not highly sensitive to the measure employed, as has been argued by Saunders (1996). In fact, including information from the work by Kennedy, Kawachi and Prothrow-Stith (1996), the same substantive conclusions about the association between income inequality and health would be reached, based on use of the Gini coefficient, Robin Hood Index or any percentile share of total income between the 10th and the 80th.

Furthermore, in a new analysis conducted by Kawachi and Kennedy (in press) they examined the associations between eight different commonly used measures of income distribution and age-adjusted total mortality in the USA. All measures were highly correlated with each other, and showed significant associations with mortality, ranging from $r=0.50$ to 0.66 , even after adjustment for median income and poverty level. They state, 'Thus, the choice of income distribution measure does not appear to alter the conclusion that income inequality is linked to higher mortality.'

It is true however, that the income distributions used in the original analyses by Kaplan and colleagues (1996b) and Kennedy and colleagues (1996) did not fully take into account the impact of taxes, transfers and household size, a point made by Judge (1996) in a more recent letter criticizing our study and the work of Kennedy and colleagues (1996). In response to his critique of our work, we addressed these concerns in two ways, by accounting for taxes, benefits and household size at both the aggregate and individual levels (Kaplan, Lynch, Pamuk, Cohen, \& Balfour, 1996a).

In our original article, we reported an incomeadjusted association between the share held by the least well-off 50 percent of the population 
and mortality of $r=-0.57$ (Kaplan et al., 1996b). This association was $r=-0.49$, after additional aggregate adjustment for average household size (a proxy for household composition); maximum welfare/food stamp payments; and the maximum difference between state income-tax brackets (a proxy for the redistributive effect of state income-tax). Subject to the limitations of ecologic adjustment of this association, taking account of these factors appears to make little difference.

To capture fully the effects of taxes, benefits and household composition on the actual distribution of disposable income, we used data kindly provided by Professor Timothy Smeeding, the Director of the Luxembourg Income Study. The association between inequality and mortality in the United States was examined using disposable income distributions, adjusted at the household level for cash and near cash transfers, income and payroll taxes, including the Earned Income Tax Credit, and adjusted with a household size equivalence scale (Smeeding \& Gottschalk, 1996). The LIS data were based on the US Current Population Survey (1990-1993), and included the share of household income received by the most and least well-off 20 percent of the population. We calculated directly comparable percentage shares in the 1990 US Census based data on gross income (Table 4).

The association between income inequality and mortality was virtually identical, although the absolute magnitude of income inequality in the States was reduced in LIS data. This suggests that there was no change in the ordering of the States with respect to income inequality. The relationship between income inequality and mortality was not affected by taking account of taxes, benefits and household size.

Judge has referred to the 'contentious' issue of the relationship between income distribution and mortality, but we are aware of only three criticisms of the data supporting this relationship: two are authored by Judge (1995, 1996) and the third by Saunders (1996) merely repeats these same criticisms. Further progress on the relationship between income inequality and health will be made by examining different measures of income distribution, with a variety of health outcomes, across a number of geopolitical levels, and by careful consideration of how income distribution might influence the health of individuals and societies, and that is where we now turn our attention.

\section{How might inequitable distribution of income impact health?}

We have already alluded to the mathematical relationship between income distribution and population health, based on a positive asymptotic association between absolute income and health. For this reason, areas that have greater income inequality will have lower overall levels of population health because those at the bottom of the income distribution in a high inequality area will have lost more health than those at the top have gained. The proof of this association is set out in Preston (1975), Rodgers (1979) and by Kawachi, Levine, Miller, Lasch and Amick (1994). As Kawach and colleagues argue, the non-linear relationship between income and mortality is a 'sufficient' (1994, their emphasis) condition for income distribution to be a determinant of mortality, but it is probably not the most interesting or, indeed, most important part of understanding how income distribution impacts health.

We should point out there are very little data to inform this discussion. Furthermore, we are not trying to propose a particular causal pathway between income inequality and health, but rather

Table 4. Associations between inequality and mortality for the 50 United States, adjusted for median income (Kaplan et al., 1996a)

\begin{tabular}{lll}
\hline & \multicolumn{2}{c}{ Share of total state income held by } \\
\cline { 2 - 3 } & Least well-off $20 \%$ & Most well-off $20 \%$ \\
\hline Disposable income (LIS) & $-0.60(p<.001)$ & $0.45(p<.001)$ \\
'Raw income' (US Census) & $-0.61(p<.001)$ & $0.47(p<.001)$ \\
\hline
\end{tabular}


suggest a range of factors that might be considered in developing a conceptual model of 'what fits where' in the association between income inequality and health. For this reason, the issues we discuss here are at least somewhat speculative, and highlight the need for more theoretical work to guide research. The importance of this task cannot be understated, because it is only through the development of comprehensive conceptual models, that we can sensibly address issues about adjustment for confounding that have been raised by Judge (1995). As we argue elsewhere, adjustment for confounding should be based on an underlying causal model relating a putative exposure and a health outcome, and is not primarily a technical or mechanical issue (Lynch et al., 1996, 1997).

Put in its simplest form, our basic hypothesis about the relation between income inequality and health has two intertwining strands. First, inequitable income distribution may be associated with a set of social processes and policies that systematically underinvest in human, physical, health and social infrastructure, and this underinvestment may have health consequences. Second, inequitable income distribution may have direct consequences on people's perceptions of their social environment that influence their health. In developing a conceptual framework for understanding how income distribution affects health, it may be worthwhile to reflect on what mechanisms and explanations have been proposed for how income affects health at the individual level. In an interesting and informative article, Macintyre (1997) has re-examined the Black Report (Townsend \& Davidson, 1982) and developed both 'hard' and 'soft' interpretations of the explanations they proposed. The Black Report suggested four categories of explanation: artefactual; social selection; materialist; and cultural/behavioral/psychosocial. While these explanations were conceptualized at the individual level, a similar approach might be applied at the ecologic level. Perhaps by examining some ecologic counterparts of these explanations for health inequalities, we can begin to develop an understanding of how income inequality influences health. To some extent, we have already discussed the issues which would form the basis of an artefactual explanation for an association between income inequality and health status, in our comments about Judge's
(1995, 1996) criticisms. For this reason, we will focus the discussion on material, cultural, behavioral and psychosocial factors at the ecologic level that may be linked with income inequality and influence health.

In thinking about how material, cultural, behavioral and psychosocial factors might be associated with income inequality and health status at the aggregate level, we feel that it is important to understand that some of these 'categories of explanation' are linked, as indeed they are at the individual level. At the outset, it may be helpful to pose the question like this: What sorts of characteristics and conditions are likely to exist in a country, state or region that also tolerates high levels of inequality in the distribution of income? In a general sense, we think the answer to this question is that areas that tolerate high-income inequality are also less likely to support the human, physical, cultural, civic and health resources in that area, independent of the absolute level of income.

For instance, what differences might exist between two areas that have the same average absolute level of income, but one allows a smaller share of the total income to be received by the least well-off 50 percent off the population? It may not be surprising to find that the higher inequality area also provides less equitable support for education, affordable housing, good roads or environmental protection. In fact there is some evidence for this in our study comparing the 50 States on inequality and mortality (Kaplan et al., 1996b). We showed in that study how states with more equitable income distribution had higher spending on education per capita $(r=0.32, p=.02)$; had more library books per capita $(r=0.42, p=$ $.002)$; had lower proportions of their populations without any health insurance $(r=-0.45, p=$ $.002)$; had lower rates of violent crime $(r=$ $-0.70, p=.0001$ ), and tolerated lower proportions of their population in jail $(r=-0.44, p=$ .01 ), even after accounting for differences in the absolute level of median income in each state. In fact, the distributional measure of income we used in this study was more strongly associated with these characteristics than was the absolute income level.

There may be a plethora of other characteristics of high-income inequality areas that influence health status directly and indirectly. Do 
higher inequality areas have less immunization or tuberculosis control programs; fewer initiatives in public health education about smoking, diet or exercise; less strict environmental pollution standards; provide less support for cultural festivals, civic performances and art shows; have higher concentrations of cigarette and alcohol advertising; or are more likely to tolerate racial and gender discrimination? It is also important for us to point out that it is not just spending by governments on social programs that determines overall inequality of income distribution. In the popular press, it is commonplace to read reports about the ever widening gaps in wages within private-sector employment (Timmins, 1996). It is perhaps emblematic of the nature of income inequality that at the same time workers are pressured to restrict their claims for higher wages, the incomes and benefits received by some top executives in the private sector have risen to unprecedented levels.

It is also possible that high-income inequality creates an undesirable psychosocial climate which directly influences health by affecting the level of social cohesion. A recent paper by Kawachi, Kennedy, Lochner and Prothrow-Stith (in press) explored the relation between income inequality and social capital, defined as features of 'social organization, such as civic participation, norms of reciprocity, and trust in others, that facilitate cooperation and mutual benefit' (p. 5). The idea of 'social capital' was proposed by Coleman $(1987,1990)$ in the context of educational reform, and used by Putnam (1993) in relation to the performance of democratic institutions. Social capital refers to the stock of investments, resources and networks that produce social cohesion, trust and a willingness to engage in community activities. Kawachi and colleagues (in press) showed that income inequality (measured by the Robin Hood Index) was strongly associated with levels of social trust $(r=0.73, p<.0001)$ and group membership $(r=-0.46, p<.01)$ for both blacks and whites. They concluded that social capital was an important mediating variable in the relation between income inequality and mortality.

Unlike physical or human capital, which are private goods, social capital is a public good that is created as a by-product of social relationships. Like most types of public goods, social capital tends to be underproduced if left to the market. A major finding of this study (which needs to be confirmed in longitudinal studies) is that the size of the gap between the rich and the poor is powerfully, and negatively related to the level of investment in social capital. (p. 15)

However, more work needs to be done clarifying the pathways by which social capital, or the lack of it is related to health.

Wilkinson (1992) and Kawachi and colleagues (1994) argued that evidence for an association between income distribution and health, forces a shift in emphasis away from the absolute level of income to considerations of how relative income influences health. From a more materialist position, we have argued that income inequality (relative income) may be a marker for a set of other concrete societal characteristics and policies that influence health. However, it is also possible that income inequality directly influences health through individual appraisals of relative position in the social order. Wilkinson (1992, p. 168) states that 'The social consequences of people's differing circumstances in terms of stress, self esteem and social relations may now be one of the most important influences on health.'

Kawachi and colleagues (1994) elaborate this thinking by pointing out that most people living in poverty in industrialized nations, still have access to heat, water, electricity and television. By absolute standards, if they were living in less-developed countries, these same people would be considered rich, but in fact they are 'poor' in relation to those who live around them, not to some absolute standard. This is one of the reasons that the 'poverty level' must be periodically reset-it is not based on an absolute, rather it is defined by a society's changing living standards. To use a simple example: if there were two areas that had the same absolute income, but differed according to the distribution of that total income, people in the least well-off 50 percent of the population of the more unequal area would perceive themselves as being more relatively deprived than would the same group in a more equitable area. In other words, they would 'feel' the higher inequality around them. 
It is this appraisal of relative well-being that may provide a psychosocially mediated link between income inequality and health status. Indeed, there are a number of theories for how such relational appraisals might be deleterious to health. In discussing how experiences of inequality might produce a gap between aspirations and rewards, Kawachi and colleagues (1994) suggested how these perceptions of inequality might translate into stress, frustration, depression, anxiety, hostility or, for that matter, any number of health damaging psychosocial characteristics and behaviors. Our point here is that there appears to be plausible theories within the field of health psychology to explain how living in a climate of income inequality might produce increased levels of psychosocial stress, or the initiation and maintenance of behaviors that could be detrimental to health. This psychosocial aspect of income inequality may also help to explain partly why those not quite at the top of the income distribution are thought to have somewhat poorer health than would those at the very top (Rose \& Marmot, 1981). In rich countries, the negative impact of inequality on health would not be limited to the bottom of the social pyramid, because appraisal of relative position would extend to everyone in the hierarchy, so that even those with good incomes might feel 'relatively deprived' compared to the super rich.

However, it is vital to remind ourselves that any psychosocial understanding of income inequality is inextricably linked to the material features of the environment. It would be difficult to understand fully the psychologically 'immiserating' effects of relative position in the social order without appreciating the material factors that help to form the basis of this perception (Engels, 1848/1958; Marx, 1867/1967). Bourdieu (1984) has demonstrated in some detail how individuals embody and display their place in the social structure through their tastes for art, music, food and reading material. People use a variety of information about their environment to form perceptions of their relative position in the socio-economic order, from material possessions and financial strain, to the levels of noise and pollution they experience, to how much violence and crime they encounter, to the friendliness of strangers on the streets where they live, to the choices available for housing, education and medical care. These individual perceptions are initiated and reinforced by the day-to-day conditions, events and experiences of living in a particular environment of income inequality, and it is not too difficult to imagine that the everyday experiences of living in a high inequality area presents different images from those encountered in a more equal environment. Although anecdotal evidence, it is commonplace to hear international visitors to certain parts of the United States, from more egalitarian countries, comment upon the stark contrast between homelessness and extreme wealth, that is less evident in their own countries.

\section{Where to from here? Challenges and possibilities}

Research on the relationship between income distribution and health is in its infancy, so there are many issues to be explored. We conclude this article by briefly describing some of the challenges and important possibilities in better understanding the link between inequality of income distribution and health.

\section{The challenges}

Measuring inequality in income distribution Although, there is some evidence presented in this article, to show that the crosssectional association between income inequality and mortality within the 50 States was not sensitive to how income distribution was measured (Kaplan et al., 1996b; Kawachi \& Kennedy, in press; Kennedy, Kawachi, \& ProthrowStith, 1996; and see corrections in British Medical Journal 312, 11 May 1996), it remains an open question, whether this is the case for prospective analyses, for other health outcomes, or for other levels of aggregation. Measures of income distribution may vary to the extent they differentiate between changes in the shape of particular parts of the income distribution. The choice of a measure of inequality would be aided by the development of a conceptual model of how income distribution affects a particular health outcome.

For example, it is possible to construct a variety of measures that express ratios of the total income received by any particular proportion of the population. In studying how change in income distribution over time was related to 
health, we think it would be informative to know if changes in health status were related to the 'rich getting richer' or the 'poor getting poorer'. Consequently, inequality measures that assessed changes in the ratio of the income share held at the 90th compared to the 50th percentile (90:50), and the 50th compared to the 10th percentile (50:10) could begin to assess whether population health levels were more strongly related to how much those at the bottom of the income distribution were pushed away or toward the middle of the distribution (50:10), compared to income share gains or losses at the top of the income distribution (90:50) (Daly, Duncan, Kaplan, \& Lynch, 1997).

In addition, it will be important to know more about how different definitions of income affect the association with health outcomes. Judge $(1995,1996)$ has correctly pointed out that failure to account for governmental policies that tax and transfer benefits will overstate the extent of inequality. One important issue here, may be whether there are particular types of tax and transfer benefits that blunt the health impacts of 'raw' market inequality. There are potentially important implications for public policy in this type of research, and, indeed, we are currently attempting to examine this issue with United States data.

One of the most important areas of future research on issues of income distribution and health involves measuring 'wealth' and not income. Wealth refers to the total value of assets net of outstanding debt, and typically includes financial wealth (bank accounts, stocks, bonds, life insurance, etc.), value of housing and businesses, consumer durables like cars and major appliances, plus the value of pensions and retirement programs. It is important to explore the association between the distribution of wealth and health, because wealth better captures the long-term capacity to ensure economic security from fluctuations in income level, and is powerfully related to the exercise of economic, political and social influence. For these reasons, income distribution may be a poor measure of how material, financial, political and social resources are actually distributed.

Krugman (1992) has shown that income distribution statistics may greatly underestimate the true concentration of wealth. In the United States while the top 1 percent of income earners receives about 12 percent of the total pretax income, they hold more than 37 percent of the wealth. From 1983 to 1989 , the top 1 percent of wealth holders in the United States received 62 percent of the total gain in marketable net worth (Wolff, 1995). The next 19 percent of wealth holders received 37 percent of the gains, while the bottom 80 percent of the population received only 1 percent. 'This pattern represents a distinct turnaround from the 1962-83 period, when every group enjoyed some share of the overall wealth growth and the gains were roughly in proportion to the share of wealth held by each in 1962' (Wolff, 1995, p. 12).

Geopolitical aggregation To date, evidence of negative health effects of inequality in the distribution of income has been limited to studies comparing nations and among the 50 US States. Income distribution is a structural characteristic of a social system, however it is unclear how different levels of geopolitical aggregation might affect its association with health status. The basic question concerns deciding what level of geopolitical aggregation is an appropriate 'unit of analysis'. If inequitable income distribution is related to a variety of other structural characteristics, at what level should these factors influence health statusnational, state or province, county or local authority, city or neighborhood? To some extent, we would expect the association between income distribution and health to weaken as the level of geopolitical aggregation became more local. For instance, if everyone in a neighborhood was unemployed, there would be little inequality in income distribution, but the health status of the neighborhood would be poor.

In terms of a more psychosocial interpretation of the link between income distribution and health, information about relative position in the social hierarchy may not only be derived from localized references to the immediate social and economic surroundings of a neighborhood, city or state. Technologies like television and movies allow comparisons across a wide economic, social, behavioral and cultural range. We are currently examining some of these issues by studying the association between income distribution and health outcomes in 283 metropoli$\tan$ areas of the United States. We hope that analyses such as these may provide clues as to 
how income distribution impacts health status, as there will be both more variation in income distribution and mortality and greater potential for local features of the geopolitical environment (e.g. specifically focused local public initiatives on issues like affordable public housing, access to prenatal care or violence prevention) to exert their impact on the link between income distribution and health.

Interpreting the association between inequitable income distribution and health As we stated earlier, one important task in advancing understanding of the association between income distribution and health is the development of comprehensive conceptual models. Thinking about such frameworks will be aided by empirical investigations, and may need to consider issues like:

- the pathways through which income distribution impacts health, and distinguishing between 'confounders', and factors in the causal pathway

- how inequitable income distribution is related to health outcomes that have different latency periods (e.g. cardiovascular disease vs suicide or homicide)

- how to understand and model the separate and joint effects of absolute income and income distribution, and

- how to understand differences in the association of inequality in income distribution and health between the young and the old, the rich and the poor, men and women, or between racial and ethnic groups.

\section{The possibilities}

Studies on the relationship between inequality of income distribution and health could not be more timely. In recent years, there has been a surge of scientific interest, particularly in economics, to document the extent, nature and trends in income inequality both internationally and within individual countries (Danziger \& Gottschalk, 1995; Reed, Haber, \& Mameesh, 1996; Smeeding \& Gottschalk, 1996). While interpretation of these data has been vigorously debated in political circles, there now seems little doubt about the validity of the evidence showing increased income inequality since the 1980s (Krugman, 1992).

Table 5 presents data from the Luxembourg Income Study that shows changes in income inequality between 1967 and 1992 for a variety of selected countries. In addition, it shows changes in child poverty rates over the same time period. In countries like the United Kingdom and the United States, there have been large increases in income inequality and in child poverty rates. These data suggest that at the same time as overall income inequality has increased there has been a simultaneous assault on the youngest and most vulnerable members of the society, by pushing more families with

Table 5. Changes in income inequality and child poverty rate (1967-1992)*

\begin{tabular}{lcc}
\hline Country & \% Change in inequality & \% Change in child poverty \\
\hline UK & $+>30$ & $+>30$ \\
USA & $+16-29$ & $+>30$ \\
Sweden & $+16-29$ & $->5$ \\
Australia & $+10-15$ & 0 \\
Denmark & $+10-15$ & $->5$ \\
Norway & $+5-10$ & $+10-15$ \\
The Netherlands & $+5-10$ & $+5-10$ \\
Belgium & $+5-10$ & $+5-10$ \\
W. Germany & 0 & $+5-10$ \\
Israel & 0 & $+5-10$ \\
Spain & 0 & 0 \\
France & 0 & 0 \\
Finland & 0 & $->5$ \\
Canada & 0 & $->5$ \\
Italy & $->5$ & $->5$ \\
\hline
\end{tabular}

\footnotetext{
* Adapted from Smeeding \& Gottschalk (1996).
} 
children into the lower end of the income distribution. In addition to negative effects on the immediate health status of these children, there may well be longer term behavioral, psychosocial and health dividends to be reaped (Lynch et al., 1997). However, these data also show that there is no necessary relation between changes in income inequality and child poverty. While Sweden witnessed similar increases in income inequality to the USA, they were able enact policies that actually reduced child poverty levels.

As Davey Smith (1996, p. 988) has pointed out, 'The only coherent argument against redistributive social policies is that they hinder overall economic growth.' The standard political argument against income redistribution is almost always framed in terms of a 'trade-off' between overall economic growth and equitable distribution of income. This is true whether the debate concerns the economies of developed or developing countries, and has usually been cast so that social spending, investment in public infrastructure and redistribution of social goods must be curtailed or delayed to ensure overall growth in the economy. The best way to improve the lot of those at the bottom of the income distribution is to enlarge the size of the 'economic pie'. The unstated assumption in this 'trickle-down' approach is that equity is derivative of growth. However, evidence is mounting that overall economic growth may be relatively ineffective in helping the disadvantaged members of the population (Cutler \& Katz, 1991). In short, the rising tide does not lift all boats evenly (Danziger \& Gottschalk, 1993).

Bruno, Ravallion and Squire (1995, p. 22) show that

there is no intrinsic trade-off between longrun efficiency and equity. In particular, policies aimed at facilitating accumulation of productive assets by the poor-when adopted in a relatively non-distorted framework-are also important instruments for achieving higher growth. The problem should not be posed as that of choosing between growth and redistribution. (WHO/SIDA, 1996)

This is a vital issue for developing and developed nations concerned not only with economic growth but with equity in health and health care.
As Bruno and colleagues (1995) suggest, the accumulation of productive assets enhances economic growth. The material presented here suggests that one of these important productive assets is health, and it is strongly related to the extent of inequitable income distribution. We hope that research on the link between inequality in the distribution of income and health status will force policy debates about income inequality to be framed, in part, in terms of its health and social consequences. Distributional aspects of the economy are important determinants of health, over and above the absolute level of income, and for those of us concerned with population health may well provide one of the most pertinent indicators of overall social well-being.

\section{References}

Antonovsky, A. (1967). Social class, life expectancy and overall mortality. Millbank Memorial Fund Quarterly, 45, 31-73.

Auster, R., Leveson, I., \& Sarachek, D. (1969). The production of health: An exploratory study. Journal of Human Resources, 4, 411-436.

Backlund, E., Sorlie, P. D., \& Johnson, N. J. (1996). The shape of the relationship between income and mortality in the United States: Evidence from the National Longitudinal Mortality Study. Annals of Epidemiology, 6, 1-9.

Ben-Shlomo, Y., White, I. R., \& Marmot, M. (1996). Does the variation in socioeconomic characteristics of an area affect mortality? British Medical Journal, 312, 1013.

Bourdieu, P. (1984) Distinction. Cambridge, MA: Harvard University Press.

Bruno, M., Ravallion, M., \& Squire, L. (1995). Equity and growth in developing countries: Old and new perspectives on the policy issues. Paper prepared for the IMF Conference on Income Distribution and Sustainable Growth, 1-2 June.

Carroll, D., Davey Smith, G., \& Bennett, P. (1996). Some observations on health and socio-economic status. Journal of Health Psychology, 1(1), 23-39.

Coleman, J. S. (1987). Families and schools. Educational Researcher (August-September), 32-38.

Coleman, J. S. (1990). The foundations of social theory. Cambridge, MA: Harvard University Press.

Cowell, F. A. (1995). Measuring inequality. Hemel Hempstead: Prentice-Hall/Harvester Wheatsheaf.

Crenshaw, E., \& Ameen, A. (1993). Dimensions of social inequality in the Third World. Population Research and Policy Review, 12, 297-313.

Cutler, D. M., \& Katz, L. F. (1991). Macroeconomic 
performance and the disadvantaged. Brookings

Papers on Economic Activity, 2, 1-74.

Daly, M., Duncan, G., Kaplan, G. A., \& Lynch, J. W. (1997). Macro-to-micro linkages in the inequality mortality relationship. Manuscript submitted for publication.

Danziger, S. H., \& Gottschalk, P. (Eds.). (1993). Uneven tides: Rising inequality in America. New York: Russell Sage.

Danziger, S. H., \& Gottschalk, P. (1995). America unequal. New York: Russell Sage.

Davey Smith, G. (1996). Income inequality and mortality: Why are they related? British Medical Journal, 312, 987-988.

Davey Smith, G., \& Egger, M. (1996). Commentary: Understanding it all-health, meta-theories, and mortality trends. British Medical Journal, 313, 1584-1585.

Duleep, H. O. (1995). Mortality and income inequality among economically developed countries. Social Security Bulletin, 58, 34-50.

Engels, F. (1958). The condition of the working class in England. (O. W. Henderson, \& W. H. Chalones, Trans.). Stanford, CA: Stanford University Press. (Original work published 1848)

Fischer, C. S., Hout, M., Jankowski, M. S., Lucas, S. R., Swidler, A., \& Voss, K. (1996). Inequality by design: Cracking the Bell curve myth. Princeton, NJ: Princeton University Press.

Flegg, A. T. (1982). Inequality of income, illiteracy and medical care as determinants of infant mortality in underdeveloped countries. Population Studies, 36, 441-458.

Fraser, G. R. (1995). Plato on social inequality [Letter to the editor]. British Medical Journal, $310,528$.

Fuchs, V. (1974). Some economic aspects of mortality in developed countries. In M. Perlman (Ed.), The economics of health and medical care (pp. 174-193). New York: Wiley.

Haan, M. N., Kaplan, G. A., \& Camacho, T. (1987). Poverty and health: Prospective evidence from the Alameda County study. American Journal of Epidemiology, 125, 989-998.

Haan, M. N., Kaplan, G. A., \& Syme, S. L. (1989). Socioeconomic status and health: Old observations and new thoughts. In. J. P. Bunker, D. S. Gomby, \& B. H. Kehrer (Eds.), Pathways to health: The role of social factors. (pp. 76-135). Menlo Park, CA: HJ Kaiser Family Foundation.

Herrnstein, R. J., \& Murray, C. (1994). The Bell curve: Intelligence and class structure in American life. New York: Free Press.

Judge, K. (1995). Income distribution and life expectancy: A critical appraisal. British Medical Journal, 311, 1282-1285.

Judge, K. (1996). Income and mortality in the United
States [Letter to the editor]. British Medical Journal, 313, 1206.

Kaplan, G. A. (1996). People and places: Contrasting perspectives on the association between social class and health. International Journal of Health Services, 26, 507-519.

Kaplan, G. A., \& Keil, J. E. (1993). Socioeconomic factors and cardiovascular disease: A review of the literature. Circulation, 88, 1973-1998.

Kaplan, G. A., Lynch, J. W., Pamuk, E. R., Cohen, R. D., \& Balfour, J. L. (1996a). Income and mortality in the United States [Letter to the editor]. British Medical Journal, 313, 1207.

Kaplan, G. A., Pamuk, E. R., Lynch, J. W., Cohen, R. D., \& Balfour, J. L. (1996b). Inequality in income and mortality in the United States: Analysis of mortality and potential pathways. British Medical Journal, 312, 999-1003.

Kawachi, I., \& Kennedy, B. P. (in press). The relationship of income inequality to mortalityDoes the choice of indicator matter? Social Science \& Medicine.

Kawachi, I., Kennedy, B. P., Lochner, K., \& Prothrow-Stith, D. (in press). Social capital, income inequality, and mortality. American Journal of Public Health.

Kawachi, I., Levine, S., Miller, S. M., Lasch, K., \& Amick, B. (1994). Income inequality and life expectancy - theory, research and policy. Boston, MA: Society and Health Working Group, Health Institute, New England School of Medicine.

Kennedy, B. P., Kawachi, I., \& Prothrow-Stith, D. (1996). Income distribution and mortality: Crosssectional ecologic study of the Robin Hood index in the United States. British Medical Journal, 312, 1004-1007.

Krieger, N., Rowley, D., Hermann, A. A., Avery, B., \& Phillips, M. T. (1993). Racism, sexism, and social class: Implications for studies of health, disease, and well-being. American Journal of Preventive Medicine, 9 (Suppl. 6), 82-122.

Krugman, P. (1992). The rich, the right and the facts. The American Prospect, 11, 19-31.

LeGrand, J. (1987). Inequalities in health. European Economic Review, 31, 182-191.

Lewontin, R. C. (1991). Biology as ideology. New York: Harper Perennial.

Lewontin, R. C., Rose, S., \& Kamin, L. J. (1984). Not in our genes: Biology, ideology and human nature. New York: Pantheon.

Lynch, J. W. (1996). Social position and health. Annals of Epidemiology, 6, 21-23.

Lynch, J. W., Kaplan, G. A., Cohen, R. D., Kauhanen, J., Wilson, T. W., Smith N. L., \& Salonen J. T. (1994). Childhood and adult socioeconomic status as predictors of mortality in Finland. Lancet, 343, 524-527. 
Lynch, J. W., Kaplan, G. A., Cohen, R. D., Tuomilehto, J., \& Salonen, J. T. (1996). Do cardiovascular risk factors explain the relation between socioeconomic status, risk of all-cause mortality, cardiovascular mortality and acute myocardial infarction? American Journal of Epidemiology, 144, 934-942.

Lynch, J. W., Kaplan, G. A., \& Salonen, J. T. (1997) Why do poor people behave poorly? Variation in adult health behaviours and psychosocial characteristics by stages of the socioeconomic lifecourse. Social Science \& Medicine, 44, 809-820.

Lynch, J. W., Kaplan, G. A., Salonen, R., Cohen, R. D., \& Salonen J. T. (1995). Socioeconomic status and carotid atherosclerosis. Circulation, 92, 1786-1792.

Lynch, J. W., Krause, N., Kaplan, G. A., Cohen, R. D., Tuomilehto, J., \& Salonen, J. T. (1997). Workplace conditions, socioeconomic status, and the risk of mortality and acute myocardial infarction: The Kuopio ischemic heart disease risk factor study. American Journal of Public Health, 87(4): 617-622.

Macintyre, S. (1997). The Black report and beyond: What are the issues? Social Science \& Medicine, 44, 723-746.

Macintyre, S., Maciver, S., \& Sooman A. (1993). Area, class and health: Should we be focusing on places or people? Journal of Social Policy, 22, 213-234.

Marmot, M. G., Davey Smith, G., Stansfeld, D., Patel, C., North, F., Head, J., White, I., Brunner, E., \& Fenney, A. (1991). Health inequalities among British civil servants: The Whitehall II study. Lancet, 337, 1387-1392.

Marx, K. (1967). Capital: A Critique of Political Economy (Vol. 1). New York: International Publishers. (Original work published 1867)

McCord, C., \& Freeman, H. P. (1990). Excess mortality in Harlem. New England Journal of Medicine, 322, 173-177.

McIsaac, S., \& Wilkinson, R. G. (1995). Cause of death, income distribution, and problems of response rates. Luxembourg: Luxembourg Income Study Working Paper Series, No. 136.

Merva, M., \& Fowles, R. (1993). Effects of diminished economic opportunities and social stress: Heart attacks, stroke, crime. Washington, DC: Economic Policy Institute.

Morris, J. N. (1990). Inequalities in health: Ten years and little further on. Lancet, 336, 491-493.

Muntaner, C., Nieto, F. J., \& O’Campo, P. (1996). The Bell curve: On race, social class, and epidemiologic research. American Journal of Epidemiology, 144, 531-536.

Pampel, F. C., \& Pillai, V. K. (1986). Patterns and determinants of infant mortality in developed nations, 1950-1975. Demography, 23, 525-542.

Pappas, G., Queen, S., Hadden, W., \& Fisher, G. (1993). The increasing disparity in mortality between socioeconomic groups in the United States, 1960 and 1986. New England Journal of Medicine, 329, 103-109.

Preston, S. H. (1975). The changing relation between mortality and level of economic development. Population Studies, 29, 231-248.

Putnam, R. D. (1993). Making democracy work. Princeton, NJ: Princeton University Press.

Reed, D., Haber, M. G., \& Mameesh, L. (1996). The distribution of income in California. San Francisco: Public Policy Institute of California.

Rodgers, G. B. (1979). Income and inequality as determinants of mortality: An international crosssection analysis. Population Studies, 33, 343-351.

Rose, G., \& Marmot, M. G. (1981). Social class and coronary heart disease. British Heart Journal, 45, 13-19.

Saunders, P. (1996). Poverty, income distribution and health: An Australian study. Sydney: Social Policy Research Centre, Reports and Proceedings No. 128.

Sen, A. (1993). The economics of life and death. Scientific American (May), 40-47.

Smeeding, T. M., \& Gottschalk, P. (1996). The international evidence on income distribution in modern economies: Where do we stand? In M. Kaser \& Y.Mundlak (Eds.), Contemporary economic development reviewed, Vol. 2, Labour, food and poverty. London: Oxford University Press.

Susser, M., \& Susser, E. (1996). Choosing a future for epidemiology: II. From black boxes to Chinese boxes and eco-epidemiology. American Journal of Public Health, 86, 674-677.

Syme, S. L. (1992). Social determinants of disease. In J. M. Last \& R. B. Wallace (Eds.), MaxcyRosenau public health and preventive medicine (13th edn, pp. 687-700). Norwalk, CT: Appleton \& Lange.

Timmins, N. (1996, 21 November). Gap between rich and poor 'too wide'. Financial Times, p. 9.

Townsend, P., \& Davidson, N. (1982). Inequalities in health: The Black report. Harmondsworth: Penguin.

Waldmann, R. J. (1992). Income distribution and infant mortality. Quarterly Journal of Economics, 107, 1283-1302.

Weatherby, N. L., Nam, C. B., \& Isaac, L. W. (1983). Development inequality, health care, and mortality at the older ages: A cross-national analysis. Demography, 20, 27-43.

Wennemo, I. (1993). Infant mortality, public policy and inequality $-\mathrm{A}$ comparison of 18 industrialized 


\section{LYNCH \& KAPLAN}

countries 1950-85. Sociology of Health and Illness, 15, 429-446.

Wilkinson, R. G. (1986). Income and mortality. In Class and health: Research and longitudinal data (pp. 88-114). London: Tavistock.

Wilkinson, R. G. (1989). Class mortality differentials, income distribution and trends in poverty 1921-1981. Journal of Social Policy, 18, 307-335.

Wilkinson, R. G. (1992). Income distribution and life expectancy. British Medical Journal, 304, 165-168.

Wilkinson, R. G. (1993a). Income and health. In Health, wealth and poverty. London: Medical World/SHA.
Wilkinson, R. G. (1993b). Unfair shares. Ilford: Barnardos.

Wilkinson, R. G. (1995). Commentary: A reply to Ken Judge: Mistaken criticisms ignore overwhelming evidence. British Medical Journal, 311, 1285-1287.

Will, G. (1995, 24 April). What's behind income disparity? San Francisco Chronicle.

Wolff, E. N. (1995). Top heavy. A study of the increasing inequality of wealth in America. New York: Twentieth Century Fund Press.

World Health Organization/Swedish International Development Cooperation Agency (1996). Equity in health and health care: A WHO/SIDA initiative. Geneva: WHO. 